\title{
Application of dynamic benchmarking of rotating machinery for eMaintenance
}

\author{
Galar Diego \\ Lulea University of Technology \\ Division of Operation and Maintenance Engineering \\ 0920491000 \\ diego.galar@Itu.se
}

\author{
Berges, Luis \\ University of Zaragoza \\ Manufacturing and Design Engineering Department \\ 34976761000 \\ bergesl@unizar.es
}

\begin{abstract}
The vibration analysis and condition monitoring technology is based on comparison of measurements obtained with benchmarks suggested by manufacturers or standards. In this case, the references provided by current rules are static and independent of parameters such as age or environmental conditions in which the machine is analyzed.
\end{abstract}

New communication technologies allow the integration of eMaintenance systems, production and real-time data or the result of vibration routes. The integration of all these data allows Data mining and extraction of parameters to be incorporated into decision-making typical of CBM, such as repairs, downtime, overhauls etc.

This paper proposes the use of indicators that result from data mining as a reference dynamic, not static as proposed by the standard. The application of these references to the decision making process of the maintenance manager avoids unnecessary repairs caused by false alarms and thus prolongs the life of the equipment, resulting in the improvement of parameters such as the MTBF, in a eMaintenance system.

\section{Keywords}

OFVL, vibration, benchmark, indicator.

\section{INTRODUCTION}

Commonly non-destructive methods are used for diagnosis of machinery whose failure modes are hidden and they don't show a visible pathology to the operator. The non-detectability of such faults has promoted the use of technologies in particular the analysis of vibration, very successful in rotating machinery. This has meant a radical change in the planning of maintenance. Breakdowns are reduced significantly and also unplanned actions, these being replaced by interventions resulting from predictive inspections. It is therefore important that these predictions are reliable, and therefore the decision taken will be right back. Predictions unreliable and poor decisions lead to a high and unnecessary cost of having an intervention in labor, parts and lost production. Predictive maintenance program is considered successful if they avoid unnecessary intervention with these inspections, but unfortunately in most cases unnecessary repairs are performed due to false alarms. The system dynamics tells us that a perfect rotative machine should not vibrate, considering this failure mode like an an anomaly. However, this statement is partially true in the industrial world. Most machines suffer from a failure since the day of installation because

- Installations performed poorly
- $\quad$ Bad working conditions

- $\quad$ Poor design or manufacture of the machinery itself

- Adjacent equipment problems are transferred to the reference machine

This means that in the case of vibration, we find machines that vibrate since installation, due to bad baseplates, improper installation, improper piping design, hydraulic imbalance from using products that are not allowed to pump etc. In the case of old machines, with many hours of operation, the above issues have been able to generate vibration pattern hardly changed and that we must contemplate when planning any repairs since the level of inherent reliability has been reduced by this machinery . Vibration values of these equipments are not zero, and if we do comparative analysis we can create false alarms because this levels are higher than other machines in the same environment or if we use standards such as ISO 10816, these vibration levels can be in unacceptable area.

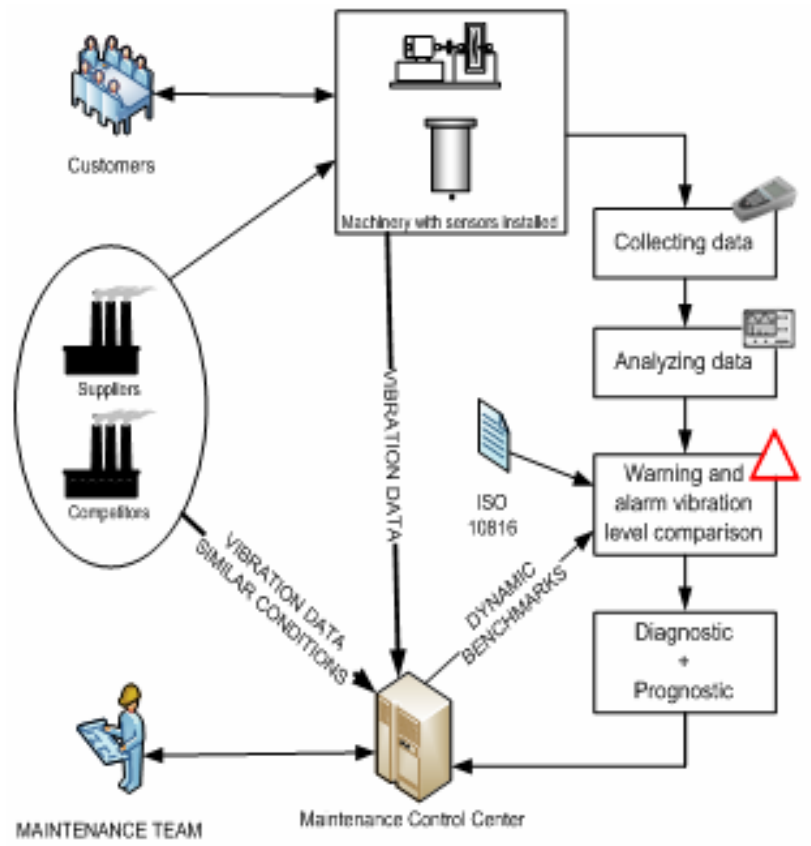

Figure 1 e-Maintenance model applied to the system

To avoid false alarms we have adopted the e-maintenance model proposed by Parida et al (2004). The model requires the existence of the monitoring techniques that allow the extraction, storage and fast processing of the parameters to consider in this case the vibration speed. In this model the benchmarks for the diagnosis 
and prognosis are not only the static of the standard, but there is a feedback of similar machines, the manufacturer etc, to obtain dynamic references.

Thus, the maintenance team has benchmarks appropriate to the age, environment and operation of machinery and can make a diagnosis more real. In this process, the customer is the most benefited, ie the direction of the company, because the machine does not stop the machinery for unnecessary repairs with the cost of interventions and production downtime

Therefore, the decision-making with the vibration data is complex, not simple and automatic application of the rule, because we think that the equipment is in poor condition when vibration due to a bad baseplate, as you can see in figure below can continue to run long time with little damage to the machine itself, and almost never invest in a renovation of the baseplate is justified by the limited impact on improving it would normally take.
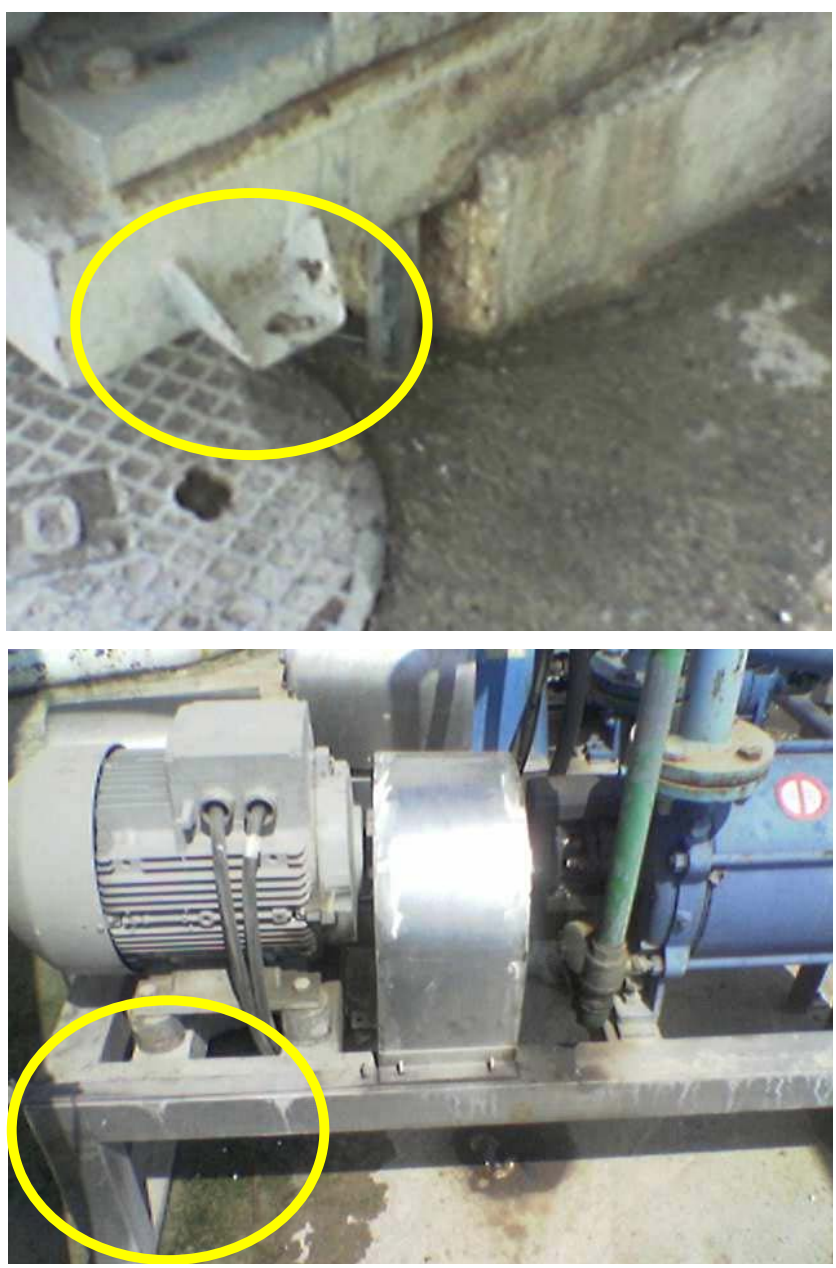

Figure 2. Examples of bad baseplate and wrong installation of centrifugal pumps.

It is therefore proposed a methodology that calculates an average dynamic vibration parameter, reference of state of large rotating machinery sets, so that we can visualize the severity of the vibration of machines, groups of machines or entire plants compared with an indicator not static, which suits the actual situation without the false alarms that strict application of the rule point to point can create. The possibility of calculating this parameter is based on the ease of data capture, data storage and subsequent processing, which would be impossible manually.

\section{VIBRATION MEASUREMENT SEVERITY}

When we classify the severity of vibration in a machine, the variable to be considered (displacement, velocity or acceleration of vibration) influences the type of rule applies, and the range of frequencies to analyze, among other factors, Kumaraswamy \& Rakesh (2002). The analysis of vibrational state of a machine in the range of $10-1000 \mathrm{~Hz}$ is usually done often in terms of the speed of vibration, as a parameter is almost independent of frequency in this range, making it easier to make a measurement easy on the severity of vibration in a machine.

In rotating machines with speed in the range of 600 to 12,000 rpm, the RMS amplitudes of vibration velocity, usually corresponds quite well with the level of severity of it. The most common values used to display the severity are the peak and RMS, W de Silva (1999). Second one is much more used and included in current regulations. Thus, the International Standards Organization (ISO) defines as "vibration severity", the largest RMS value of vibration velocity amplitude obtained in the frequency band $10-1000 \mathrm{~Hz}$ and measured at predetermined points of the structure, usually measures at the top of the bearings or supports.

\begin{tabular}{|c|c|c|c|c|c|c|}
\hline & & VIBR & ION SE & ERITY P & ISO 1 & \\
\hline & Machi & & Class I & Class II & Class III & Class IV \\
\hline & $\mathrm{in} / \mathrm{s}$ & $\mathrm{mm} / \mathrm{s}$ & machines & $\begin{array}{l}\text { medium } \\
\text { machines }\end{array}$ & $\begin{array}{l}\text { large rigid } \\
\text { foundation }\end{array}$ & $\begin{array}{l}\text { large soft } \\
\text { foundation }\end{array}$ \\
\hline & 0.01 & 0.28 & & & & \\
\hline & 0.02 & 0.45 & & & & \\
\hline है & 0.03 & 0.71 & & & & \\
\hline 5 & 0.04 & 1.12 & & & & \\
\hline : & 0.07 & 1.80 & & & & \\
\hline 응 & 0.11 & 2.80 & & satis & ctory & \\
\hline 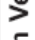 & 0.18 & 4.50 & & & & \\
\hline 으 & 0.28 & 7.10 & & unsat & actory & \\
\hline \% & 0.44 & 11.2 & & & & \\
\hline 造 & 0.70 & 18.0 & & & & \\
\hline & 0.71 & 28.0 & & unac & ptable & \\
\hline & 1.10 & 45.0 & & & & \\
\hline
\end{tabular}

Table 1. Vibration severity to ISO 2372 / ISO 10816

As shown in the table, the severity of vibration is divided into four ranges: Good, Satisfactory, Unsatisfactory or Unacceptable. When we are using ISO 2372 or ISO10816, the machine should be classified in the appropriate class, obtain the RMS value of vibration speed from 600 to 60,000 RPM (the aforementioned band of $10-1000 \mathrm{~Hz}$ ) and locate in the table the area where the machine is. Normally, it is considered that the severity of vibration of the machine remains unchanged, if you have always the same RMS value of vibration velocity amplitude in the frequency range 10-1000 Hz.

However, these reference values proposed in the standard are not adapted to the reality of old machinery or machinery installation 
defects. That is why the implementation of the rule may create unnecessary false alarms, when applied to this type of machinery. The benchmarks are static and not adapted to the age, condition of machinery or environment in which it is preserved.

The traditional way proposes the standard for comparing the vibration measured with the reference values is point to point, that is, in the case of a centrifugal pump as seen in the figure, the eight speed values measured in axial vibration horizontal and vertical would be compared with the value of the ISO. After this comparison, the severity is associated to the point where the vibration is higher.

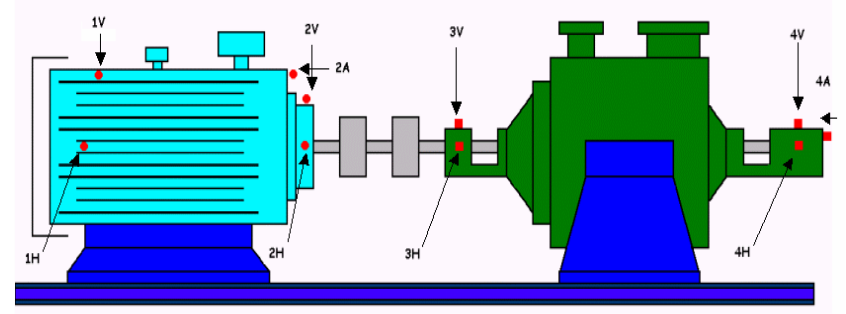

Figure 3. Location of measurement points of vibration in a centrifugal pump

This way of comparing point by point denies the possibility of disagreement between vibrations in different locations due to age or installation problems mentioned, so any of it can lead to false alarms and unnecessary interventions.

To avoid the kind of failures leading to false alarms as a bad baseplate, it is proposed to adopt the OFVL, Overall Factory Vibration Level as suggested Galar et al. (2009), as the second parameter of comparison in making decisions regarding repairs or overhaul.

The expression of the parameter OFVL (Overall Vibration Level Factory) is therefore:

$$
\text { OFVL }=\frac{\sum_{i=0}^{n} P_{i} V_{i}}{\sum_{i=0}^{n} P_{i}}
$$

Where $V_{i}$ is the average vibration of machine $\mathrm{i}$;

$$
P_{i} \text { is the power installed in the machine } \mathrm{i} \text {; }
$$

We therefore generalize the expression of the average vibration as follows:

$$
V_{\text {average }}=\frac{\sum_{i=1}^{n} v_{i} V_{i}}{\sum_{i=1}^{n} v_{i}}
$$

Where ${ }^{V_{i}}$ represents the speed associated to the point $\mathrm{i}$
$V_{i}$ $V_{i}$ represents the vibration velocity measured at the point $i$, where $\mathrm{n}$ is the total points measured: horizontal, vertical and axial, no bearings housing.

$P_{i}$ represents the power installed in the machine $\mathrm{i}$ and $\mathrm{n}$ the number of machines included in the search of the global average of vibration. With these data we can also calculate the average power installed per machine:

$$
P_{\text {average }}=\frac{\sum_{i=0}^{n} P_{i}}{n}
$$

As can be seen in the figure below, the three values that are proposed to be considered in making decisions for the maintenance team are: the value of vibration measured on the machine, the value that provides the standard for that particular machine and OFVL obtained from all available systems in the plant. The consideration of these three parameters improves the sensitivity of the system. Historically, only the data obtained with the standard vibration on a comparison point to point were considered. However, the capacity for collection, storage and calculation of condition monitoring equipment can accelerate the delivery of OFVL and the average values of vibration machine.

Online performance monitoring and data capture has special importance in power plants and in equipment such as pumps and compressors Kim \& Joo (2005) and Wyatt (2004). That is why there are many ways to collect data, transport and process. With these data, we propose a second comparison outside the norm and adapted to the reality of the machines tested.

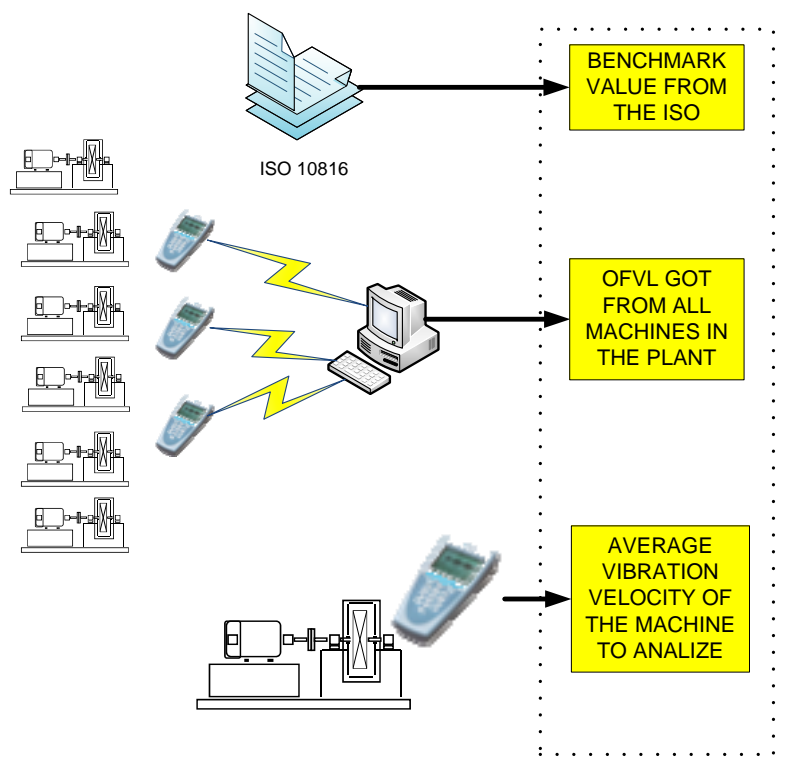

Figure 4. Available values for decision making

The decision-making process thus takes the form of figure b) below, representing a) the classical model of intervention on the machine when it exceeds the level permitted in the standard safety 
margin. The proposed model therefore reflects a first part in which we compare the average of machine vibration with reference to the rule, stopping at this stage whether any other comparison if value is within tolerable limits. This process is faster because we only have to make a single comparison rather than eight.

If this average value is higher than that proposed by the ISO, then it is compared with the value of OFVL of plant or machinery area, finding the deviation of the vibration of equipment for the machines that surround it. This allows to see the aggressiveness of the vibration about similar equipment and providing the data to the urgency of the intervention or not.

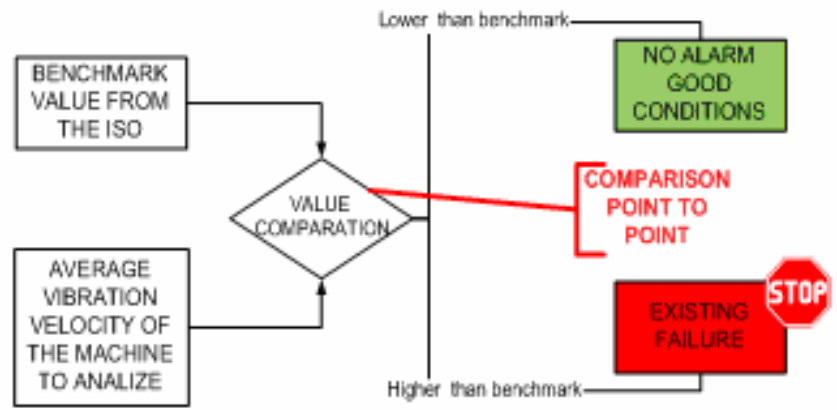

Figure 5. a) Traditional methods of making Decisions based on the standard 10816

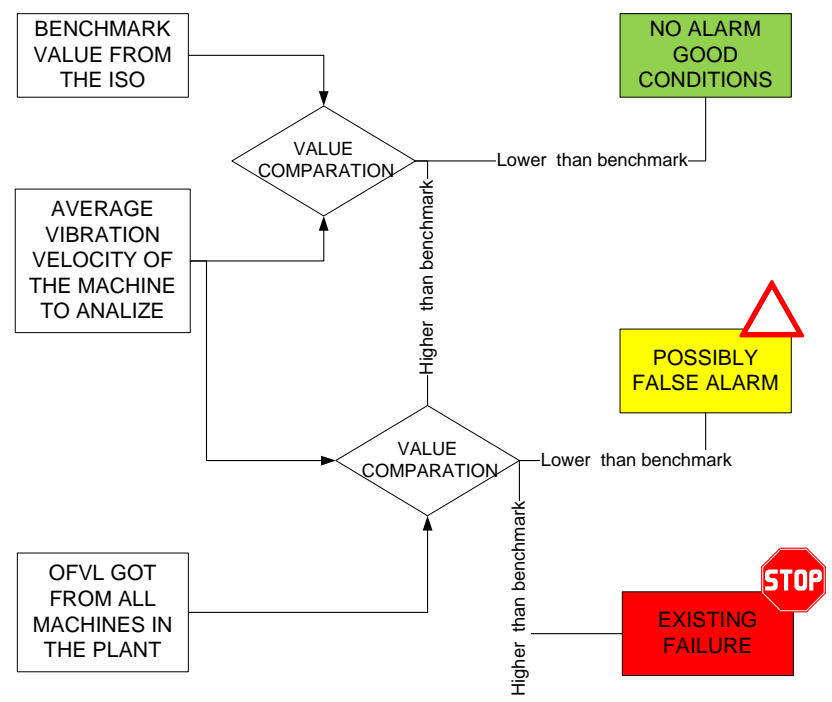

Figure 6. b) Proposed method with the calculation of OFVL.

Obtaining a significant deviation from the mean value of machine relative to global OFVL will diagnose a high severity and hence the urgency of intervention necessary. However, a value similar to global OFVL indicates a similar state of the machinery and therefore no urgency of immediate action. Often this correlation indicates a generalized state of plant aging or improper installation of a large set of machines.

\section{CALCULATION OF BENCHMARKS}

This parameter is easy to calculate manually, but when the plants acquire a certain size and number of rotating machines is high, should be systematized and automated as far as possible. To do this, there must be integration between data collection and company information systems, ie an authentic mixture of CMMS ,ERP and all data collectors which configure an eMaintenance system that supports decision making which gives . Regarding data collection, all plants that have a predictive program, perform vibration measurements with three different types of equipment, Girdhar (2004):

- Absolute value data collectors.

- $\quad$ Collectors which are spectrum analyzers.

- $\quad$ Permanent monitoring and surveillance systems.
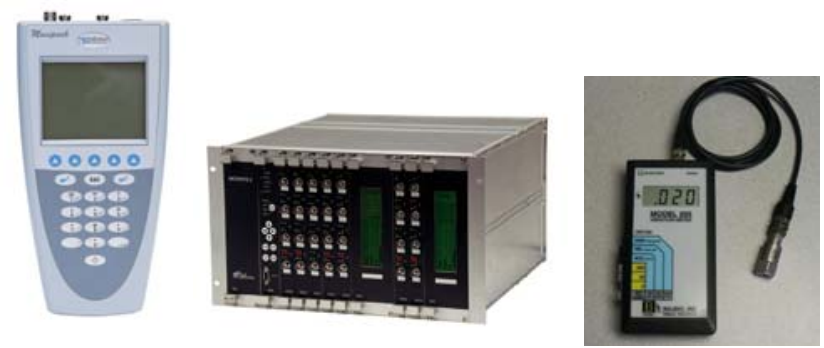

\section{a) Collector-Analyzer b) Continuous monitoring c) absolute} Meter

Figure 7. Types of vibration meters.

The data contained in the measuring equipment are automatically dumped to the computer system in the post-measurement. The highest quality measure was performed with continuous monitored by the repetitiveness of it. This repeatability is achieved by holding the sensor itself because it is attached to machines and do not need to measure it with the hand holding. The absolute basic gauges generally have no memory or too small, so you have to save the values in other media and transfer into the system.

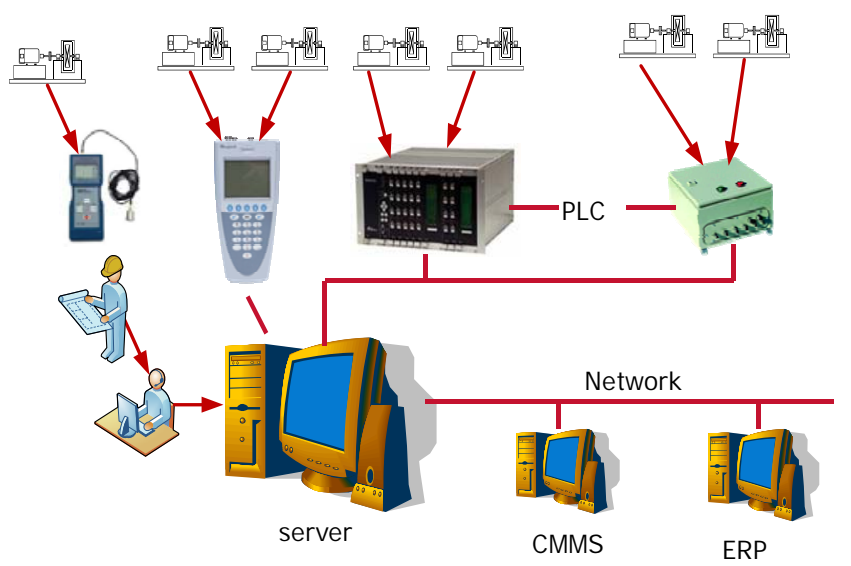

Figure 8. Types of measures and process of collecting them

Once all the data, the parameter calculation is simple because the machine data sheets in the CMMS and the PDM analysis software often have the powers and frequencies of rotation of the elements. 
This software also have the possibility of rapid export to spreadsheets which streamlines the process.

Measurement systems in firms with strong monitoring component, due to the criticality of some elements can achieve a complex structure, which may include several units of the equipment described with several dozen accelerometers as described by Reeves (1998). These systems respond to the need to measure both the acceleration, velocity or displacement in a very large set of machines with different criticality, rotational speeds and power installed

This is where you need a connection or interface between the entire CBM system and installed in the plant CMMS, necessarily existent, as proposed by Peters (2002). This will facilitate the OFVL parameter is calculated by the CMMS, and incorporated into the control panel of the maintenance team. This parameter can be considered as a Leading Indicator, It is not useful for immediate action but provides information on the trend of aging and deterioration of all the machines. The continuous monitored or routes are considered lagging indicators because they show a state of disrepair instant of machinery, and therefore whether or not stops, repairs or replacements.

This leading parameter will see the trend of the overall vibration and therefore the success of the predictive program, reaching as far as possible the minimum levels of vibration, or what is the same as the state system's inherent reliability.

We can see from the figure that the connectivity of the elements of measurement is increasingly high, even in multi plant structures with high geographical relocation, where data are collected by the sensors and transmitted by modem or TCP / IP collector system, which incorporates them into the CMMS or in many cases are inserted into the ERP itself. This allows the postprocessing of data, known as Data Mining, increasingly more parameters may include not only management but also for maintenance, including physical parameters involved in the predictive.

Obviously, this leading indicator has some correlation with PDM indicators. So at the beginning of the program, while descending the overall vibration, increase the number of hours devoted to PDM, until stable these two parameters. Also, the global vibration reduction plant will be strongly correlated with the reduction of faults and therefore the frequency of them. Thus we can see that with decreasing the overall value of vibration increases the MTBF to be the two in the so-called system reliability achieved, aiming at the inherent reliability

\section{CASE STUDY}

Once OFVL proposed as a key element in making decisions for interventions resulting from predictive analysis, we will analyze its usefulness in a broad set of machines, particularly in a corrugated steel mill which has multiple pump rooms very similar in speed and power but with different pathologies. The layout of the rooms is as you can see the figure below and respond to what is the cooling of a corrugated steel plant so that the criticality is high

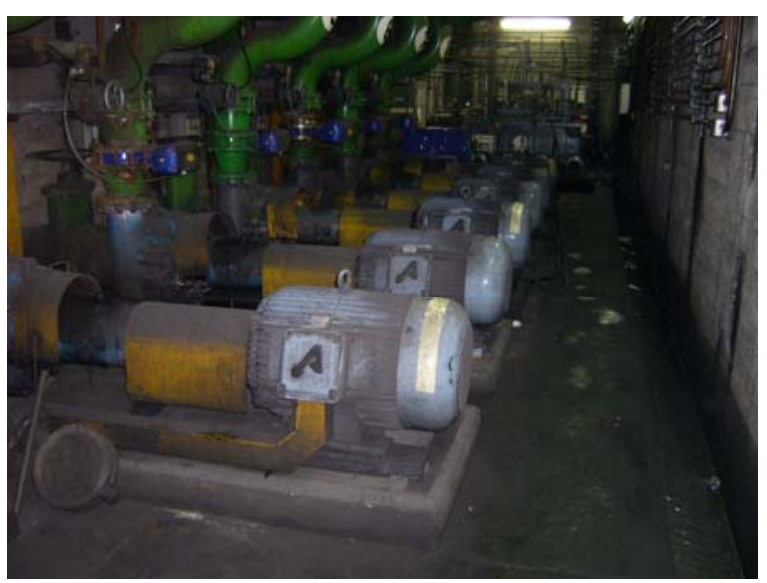

Figure 9. Pumping room 1.

\begin{tabular}{|c|c|c|c|c|c|c|c|c|c|c|}
\hline $\begin{array}{c}\text { PUMP } \\
\text { ROOMS } \\
1\end{array}$ & $\begin{array}{c}\text { Measured Parameters: } \\
\text { Vibration velocity: } \\
\mathrm{mm} / \mathrm{s}\end{array}$ \\
\hline & $\begin{array}{c}\text { PUMP } \\
2\end{array}$ & $\begin{array}{c}\text { PUMP } \\
3\end{array}$ & $\begin{array}{c}\text { PUMP } \\
5\end{array}$ & $\begin{array}{c}\text { PUMP } \\
6\end{array}$ & $\begin{array}{c}\text { PUMP } \\
8\end{array}$ & $\begin{array}{c}\text { PUMP } \\
9\end{array}$ & $\begin{array}{c}\text { PUMP } \\
14\end{array}$ & $\begin{array}{c}\text { PUMP } \\
15\end{array}$ & $\begin{array}{c}\text { PUMP } \\
17\end{array}$ & $\begin{array}{c}\text { PUMP } \\
18\end{array}$ \\
\hline $\begin{array}{c}\text { Rotation } \\
\text { speed } \\
\text { (RPM) }\end{array}$ & 1470 & 992 & 1490 & 992 & 1490 & 992 & 992 & 1489 & 1489 & 992 \\
\hline $1 \mathrm{H}$ & 0.39 & 0.805 & 1.88 & 3.8 & 2.28 & 2.02 & 1.91 & 2.55 & 1.38 & 1.6 \\
\hline $1 \mathrm{~V}$ & 0.431 & 0.539 & 1.45 & 1.96 & 1.94 & 0.834 & 2.46 & 1.51 & 1.28 & 2.25 \\
\hline $1 \mathrm{~A}$ & 0.785 & 1.08 & 1.96 & 1.61 & 1.32 & 0.929 & 1.02 & 0.996 & 1.11 & 1.55 \\
\hline $2 \mathrm{H}$ & 0.452 & 0.817 & 3.24 & 4.31 & 2.45 & 1.79 & 3.22 & 2.57 & 1.5 & 2.5 \\
\hline $2 \mathrm{~V}$ & 0.34 & 0.593 & 1.22 & 1.5 & 1.18 & 0.921 & 1.75 & 0.742 & 0.558 & 1.43 \\
\hline $3 \mathrm{H}$ & 1.02 & 0.962 & 5.2 & 3.22 & 3.39 & 3.43 & 2.64 & 2.95 & 3.03 & 5.33 \\
\hline $3 \mathrm{~V}$ & 0.816 & 0.895 & 1.56 & 1.42 & 1.83 & 2.87 & 2.5 & 1.55 & 2.59 & 3.49 \\
\hline $4 \mathrm{H}$ & 1.07 & 0.859 & 2.63 & 2.41 & 2 & 4.07 & 1.43 & 2.38 & 1.65 & 3.33 \\
\hline $4 \mathrm{~V}$ & 0.921 & 0.925 & 1.15 & 1.43 & 1.27 & 1.5 & 1.78 & 1.62 & 2.02 & 2.49 \\
\hline $4 \mathrm{~A}$ & 1.01 & 0.717 & 2.01 & 1.62 & 2.59 & 2.15 & 1.32 & 1.81 & 2.21 & 1.84 \\
\hline$V_{\text {average }}$ & 0,7235 & 0,8192 & 2,23 & 2,328 & 2,025 & 2,0514 & 2,003 & 1,8678 & 1,7328 & 2,581 \\
\hline
\end{tabular}

Table 2. Vibration in pump room 1

Once the vibration average per-machine, single parameter in a pump by the fact that only has one speed and will respond to the equation:

$V_{\text {average }}=\frac{V_{1 H}+V_{1 V}+V_{2 H}+V_{2 V}+V_{1 A}+V_{3 H}+V_{3 V}+V_{4 H}+V_{4 V}+V_{4 A}}{10}$

Once obtained the values of vibration of the machine, we can calculate the OFVL for this room, the room resulting OFVL for room $11.8361 \mathrm{~mm} / \mathrm{s}$.

\begin{tabular}{|c|c|c|c|c|c|c|c|c|c|c|}
\hline $\begin{array}{c}\text { PUMP } \\
\text { ROOMS 2 }\end{array}$ & \multicolumn{10}{|l|}{$\begin{array}{l}\text { Measured Parameters: } \\
\text { Vibration velocity: } \mathrm{mm} / \mathrm{s}\end{array}$} \\
\hline & $\begin{array}{c}\text { PUMP } \\
1\end{array}$ & $\begin{array}{c}\text { PUMP } \\
2\end{array}$ & $\begin{array}{c}\text { PUMP } \\
3\end{array}$ & $\begin{array}{c}\text { PUMP } \\
4\end{array}$ & $\begin{array}{c}\text { PUMP } \\
5\end{array}$ & $\begin{array}{c}\text { PUMP } \\
6\end{array}$ & $\begin{array}{c}\text { PUMP } \\
7\end{array}$ & $\begin{array}{c}\text { PUMP } \\
8\end{array}$ & $\begin{array}{c}\text { PUMP } \\
9\end{array}$ & $\begin{array}{c}\text { PUMP } \\
10\end{array}$ \\
\hline $\begin{array}{c}\text { Rotation } \\
\text { Speed } \\
\text { (RPM) }\end{array}$ & 992 & 992 & 992 & 992 & 1489 & 1489 & 992 & 1450 & 1489 & 992 \\
\hline $1 \mathrm{H}$ & 0.927 & 0.932 & 1.91 & 1.17 & 2.46 & 1.65 & 2.02 & 2.04 & 1.36 & 2.07 \\
\hline $1 \mathrm{~V}$ & 0.904 & 1.49 & 0.982 & 1.35 & 1.94 & 1.54 & 3.11 & 2.09 & 1.01 & 1.86 \\
\hline $1 \mathrm{~A}$ & 1.92 & 1.9 & 1.9 & 2.08 & 4.5 & 1.86 & 4.95 & 4.4 & 1.75 & 3.13 \\
\hline $2 \mathrm{H}$ & 1.04 & 0.945 & 1.1 & 1.23 & 3.04 & 1.85 & 2.77 & 2.74 & 1.52 & 1.89 \\
\hline $2 \mathrm{~V}$ & 1.24 & 1.32 & 1.03 & 1.09 & 1.87 & 1.96 & 2.08 & 1.7 & 2.28 & 2 \\
\hline $3 \mathrm{H}$ & 3.1 & 2.24 & 2.59 & 2.59 & 7.7 & 7.64 & 7.9 & 6.95 & 6.08 & 4.45 \\
\hline $3 \mathrm{~V}$ & 2.44 & 1.91 & 1.78 & 2.12 & 10.7 & 6.13 & 6.92 & 3.15 & 3.38 & 4.16 \\
\hline $4 \mathrm{H}$ & 2.46 & 1.49 & 2.13 & 1.91 & 7.89 & 5.5 & 6.18 & 4.34 & 5.25 & 4.45 \\
\hline $4 \mathrm{~V}$ & 2.1 & 2.4 & 2.5 & 2.33 & 10.3 & 5.55 & 6.1 & 2.92 & 3.5 & 5.19 \\
\hline $4 \mathrm{~A}$ & 3.03 & 2.07 & 3.09 & 3.1 & 8.13 & 6.66 & 6.73 & 2.54 & 5.71 & 2.41 \\
\hline$V_{\text {average }}$ & 1,9161 & 1,6697 & 1,9012 & 1,897 & 5,853 & 4,034 & 4,876 & 3,287 & 3,184 & 3,161 \\
\hline
\end{tabular}

Table 3. Vibration in pump room 2

In room two we get a OFVL of $3.1779 \mathrm{~mm} / \mathrm{s}$, it is noteworthy that this value is twice that obtained in room 1 . It is therefore the existence of this differential worrying in a leading parameter as OFVL and therefore constitutes an alarm 


\begin{tabular}{|c|c|c|c|c|c|c|c|c|c|c|c|}
\hline \multirow[t]{2}{*}{$\begin{array}{c}\text { PUMP } \\
\text { ROOMS } 3\end{array}$} & \multicolumn{11}{|c|}{$\begin{array}{l}\text { Measured Parameters: } \\
\text { Vibration velocity: } \mathrm{mm} / \mathrm{s}\end{array}$} \\
\hline & PUM & PUM & PUMP & PUMP & PUMP & PUMP & PUMP & PUMP & PUM & PUMP & $\begin{array}{l}\text { PUMP } \\
10\end{array}$ \\
\hline $\begin{array}{c}\text { Rotation } \\
\text { speed (RPM) }\end{array}$ & 992 & 1488 & 1450 & 1450 & s.1 & $\begin{array}{l}3.2 \\
992\end{array}$ & $\begin{array}{l}\text { o } \\
992\end{array}$ & 1470 & $\begin{array}{l}\text { Po } \\
992\end{array}$ & 985 & $\begin{array}{l}10 \\
1488\end{array}$ \\
\hline $1 \mathrm{H}$ & 2.53 & 1.89 & 0.385 & 0.786 & 0.636 & 0.461 & $\begin{array}{l}0.568 \\
\end{array}$ & 0.326 & 2.33 & 4.15 & 1.13 \\
\hline $1 \mathrm{~V}$ & $\begin{array}{l}1.8 \\
\end{array}$ & 1.27 & 0.356 & 0.262 & 1.63 & 0.522 & 0.343 & 0.843 & 1.73 & 3.18 & 0.828 \\
\hline $1 \mathrm{~A}$ & 2.59 & 3.1 & 0.678 & 1.2 & 2.7 & 0.681 & 0.907 & $\begin{array}{l}1.46 \\
\end{array}$ & 2.72 & 1.6 & 1.16 \\
\hline $2 \mathrm{H}$ & 2.42 & 1.64 & 0.38 & 0.659 & 0.918 & 0.562 & 0.632 & 0.521 & 2.83 & 5.6 & 1.16 \\
\hline $2 \mathrm{~V}$ & 1.91 & 2.42 & 0.387 & 0.534 & 1.75 & 0.443 & 0.73 & 0.545 & 1.62 & 3.39 & 1.05 \\
\hline $3 \mathrm{H}$ & & $\begin{array}{l}9.18 \\
.\end{array}$ & 0.794 & 1.17 & 2.14 & 1.01 & 1.02 & 1.11 & 1.53 & 2.07 & 3.2 \\
\hline $3 \mathrm{~V}$ & 1.94 & 4.2 & 0.52 & 0.377 & 1.7 & 1.01 & 0.65 & 0.79 & 1.13 & 0.934 & 2.55 \\
\hline $4 \mathrm{H}$ & 4.34 & 5.23 & 0.605 & 0.821 & 2.09 & 0.83 & 0.673 & 0.879 & 1.53 & 1.45 & 2.21 \\
\hline $4 \mathrm{~V}$ & 2.03 & 2.58 & 0.587 & 0.378 & 1.96 & 0.89 & 0.515 & 0.773 & 1.29 & $\begin{array}{l}1.45 \\
\end{array}$ & 2.27 \\
\hline $4 \mathrm{~A}$ & 1.74 & 1.7 & 0.536 & 0.227 & 1.17 & 0.719 & 0.393 & 0.558 & 3.07 & 2.04 & 1.26 \\
\hline Vaverag & 3,017 & 3,321 & $\begin{array}{c}0,522 \\
8\end{array}$ & $\begin{array}{c}0,641 \\
4\end{array}$ & $\begin{array}{c}1,669 \\
4\end{array}$ & $\begin{array}{c}0,712 \\
8\end{array}$ & $\begin{array}{c}0,643 \\
1\end{array}$ & $\begin{array}{c}0,780 \\
5\end{array}$ & 1,978 & $\begin{array}{c}2,586 \\
4\end{array}$ & $\begin{array}{c}1,681 \\
8\end{array}$ \\
\hline
\end{tabular}

Table 4. Vibration in pump room 3

The OFVL in this room is $1.5958 \mathrm{~mm} / \mathrm{s}$, similar to that achieved in room 1

\begin{tabular}{|c|c|c|c|c|c|c|}
\hline $\begin{array}{c}\text { PUMP } \\
\text { ROOM 4 }\end{array}$ & \multicolumn{6}{|l|}{$\begin{array}{c}\text { Measured Parameters: } \\
\text { Vibration velocity: } \mathrm{mm} / \mathrm{s}\end{array}$} \\
\hline & $\begin{array}{c}\text { PUMP } \\
3\end{array}$ & $\begin{array}{c}\text { PUMP } \\
4\end{array}$ & $\begin{array}{c}\text { PUMP } \\
5\end{array}$ & $\begin{array}{c}\text { PUMP } \\
6\end{array}$ & $\begin{array}{c}\text { PUMP } \\
7\end{array}$ & $\begin{array}{c}\text { PUMP } \\
6\end{array}$ \\
\hline $\begin{array}{c}\text { Rotation } \\
\text { Speed (RPM) }\end{array}$ & 735 & 735 & 735 & 735 & 735 & 735 \\
\hline $1 \mathrm{H}$ & 1.41 & 1.36 & 0.45 & 1.16 & 2.48 & 0.738 \\
\hline $1 \mathrm{~V}$ & 0.671 & 0.455 & 0.326 & 2.75 & 1.26 & 0.677 \\
\hline $1 \mathrm{~A}$ & 1.02 & 0.539 & 0.546 & 1.43 & 1.47 & 0.666 \\
\hline 2H & 1.48 & 1.89 & 0.835 & 1.13 & 2.05 & 1.12 \\
\hline $2 \mathrm{~V}$ & 1.14 & 0.485 & 0.566 & 1.24 & 1.26 & 0.558 \\
\hline $3 \mathrm{H}$ & 1.59 & 1.05 & 1.15 & 2.88 & 3.68 & 3.54 \\
\hline $3 \mathrm{~V}$ & 0.93 & 0.753 & 0.778 & 2.3 & 3.36 & 2.48 \\
\hline 4H & 1.47 & 1.38 & 0.936 & 5.81 & 1.96 & 1.71 \\
\hline 4V & 1.1 & 1028 & 1.05 & 3.06 & 2.17 & 2.14 \\
\hline 4A & 1.71 & 1.36 & 1.68 & 2.12 & 1.61 & 1.76 \\
\hline$V_{\text {average }}$ & 1,2521 & 1,03 & 0,8317 & 2,388 & 2,13 & 1,5389 \\
\hline
\end{tabular}

Table 5. Vibration in pump room 4

The OFVL obtained is $1.5284 \mathrm{~mm} / \mathrm{s}$, strongly correlated with the previous rooms

\begin{tabular}{|c|l|l|}
\hline $\begin{array}{c}\text { PUMP } \\
\text { ROOM 5 }\end{array}$ & \multicolumn{2}{|l|}{$\begin{array}{l}\text { Measured parameters: } \\
\text { Vibration velocity: } \\
\mathrm{mm} / \mathrm{s}\end{array}$} \\
\hline & $\begin{array}{c}\text { PUMP } \\
1\end{array}$ & $\begin{array}{c}\text { PUMP } \\
2\end{array}$ \\
\hline $\begin{array}{c}\text { Rotation speed } \\
\text { (RPM) }\end{array}$ & $\begin{array}{c}1480 \\
1480\end{array}$ & \\
\hline $1 \mathrm{H}$ & 3.87 & 0.928 \\
\hline $1 \mathrm{~V}$ & 0.809 & 1.16 \\
\hline $1 \mathrm{~A}$ & 1.3 & 2.68 \\
\hline $2 \mathrm{H}$ & 3.03 & 0.992 \\
\hline $2 \mathrm{~V}$ & 0.771 & 1.83 \\
\hline $3 \mathrm{H}$ & 2.42 & 1.52 \\
\hline $3 \mathrm{~V}$ & 1.46 & 0.922 \\
\hline $4 \mathrm{H}$ & 1.57 & 1.11 \\
\hline $4 \mathrm{~V}$ & 1.17 & 0.837 \\
\hline $4 \mathrm{~A}$ & 0.886 & 0.62 \\
\hline$V_{\text {average }}$ & 1,7286 & 1,2599 \\
\hline
\end{tabular}

Table 6. Vibration in pump room 5

OFVL room 5 is $1.4942 \mathrm{~mm} / \mathrm{s}$

\begin{tabular}{|c|c|c|c|}
\hline $\begin{array}{c}\text { PUMP } \\
\text { ROOM 6 } 6\end{array}$ & \multicolumn{3}{|c|}{$\begin{array}{c}\text { Measured Parameters: } \\
\text { Vibration velocity: } \mathrm{mm} / \mathrm{s}\end{array}$} \\
\hline & $\begin{array}{c}\text { PUMP } \\
1\end{array}$ & $\begin{array}{c}\text { PUMP } \\
2\end{array}$ & $\begin{array}{c}\text { PUMP } \\
3\end{array}$ \\
\hline $\begin{array}{c}\text { Rotation } \\
\text { speed } \\
\text { (RPM) }\end{array}$ & 1488 & 1488 & 1488 \\
\hline 1H & 2.11 & 2.58 & 1.4 \\
\hline 1V & 2.15 & 3.35 & 1.33 \\
\hline 1A & 2.86 & 5.24 & 1.74 \\
\hline 2H & 4.86 & 2.78 & 2.58 \\
\hline 2V & 4.43 & 2.87 & 1.13 \\
\hline 3H & 16.1 & 4.85 & 10.5 \\
\hline 3V & 4.74 & 3.37 & 3.82 \\
\hline 4H & 9.82 & 2.69 & 9.5 \\
\hline 4V & 4.16 & 3.59 & 2.3 \\
\hline 4A & 4.4 & 3.72 & 3.74 \\
\hline
\end{tabular}

\section{Table 7. Vibration in pump room 6}

The room OFVL 6 will be $4.29 \mathrm{~mm} / \mathrm{s}$, more than double the previous rooms which represents a serious difference

The plant OFVL, when all the engines are of equal power, will:

$$
O F V L=\frac{\sum_{i=0}^{n} P_{i} V_{i}}{\sum_{i=0}^{n} P_{i}}=\frac{P \sum_{i=0}^{n} V_{i}}{n P}=\frac{\sum_{i=0}^{n} V_{i}}{n}=2,2077 \mathrm{~mm} / \mathrm{s}
$$

When, we have rooms or areas as is the case where machinery is concentrated and can be common problems may be interesting to calculate the deviation of the zone or area OFVL respect to the globall:

\begin{tabular}{|c|c|c|c|c|c|c|}
\hline & Room 1 & Room 2 & Room 3 & Room 4 & Room 5 & Room 6 \\
\hline OFVL $(\mathrm{mm} / \mathrm{s})$ & 1,83617 & 3,1779 & 1,59583636 & 1,52845 & 1,49425 & 4,29033333 \\
\hline $\begin{array}{c}\text { OFVL Global } \\
(\mathrm{mm} / \mathrm{s})\end{array}$ & 2,20774048 & 2,20774048 & 2,20774048 & 2,20774048 & 2,20774048 & 2,20774048 \\
\hline \begin{tabular}{l} 
Deviation on the global OFVL \\
\hline
\end{tabular}$\quad-16,83 \%$ & $+43,94 \%$ & $-27,71 \%$ & $-30,76 \%$ & $-32,31 \%$ & $+94,33 \%$ \\
\hline
\end{tabular}

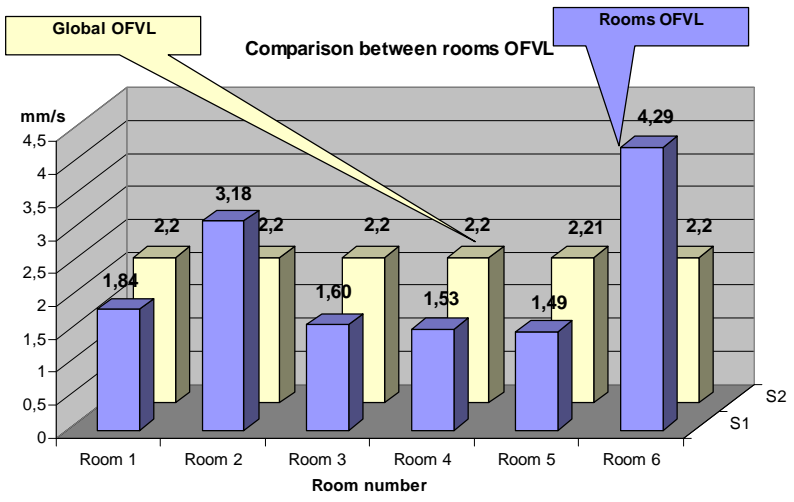

Table 8. Comparison of the different rooms OFVL with the overall plant OFVL

We can thus see a small scorecard of those rooms that present problems regarding the global OFVL, and in particular, those whose concern deviations may indicate a reproduction of a given disease across a work area. In the case study rooms can clearly see problems due to their high values for the global OFVL. The baseplate problems or loose bolts, which are presented in isolation, are avoided by the OFVL, and have no unnecessary 
alarm. It may be noted that the vibration levels of $3 \mathrm{H}$ points are averaged and smoothed so the alert level decreases significantly.

Thus we see that the comparison point to point with references to the standard reflected in many machines of the plant (those exceeding $2.8 \mathrm{~mm} / \mathrm{s}$ ), a severity that is not entirely true, since the average vibration and subsequent comparison with OFVL show that the machines are in an area of functional safety.

\section{CONCLUSIONS}

The calculation capacity of the systems software and networking and integration of all maintenance equipment in industrial plants favors the calculation of parameters considered so far by the difficulty of processing.

The incorporation of OFVL as Leading Indicator in the vibration analysis provides predictive maintenance of a capacity not achieved until now, because only lagging measures were performed to detect damage already caused.

This parameter facilitates decision making under eMaintenance system by adapting itself to the changing realities of the factory, rather than static values of the standard, which in many cases are obsolete because machines are mainly from imbalances. This standard considers only speed and power as criteria for the severity of machine without considering other factors such as the environment, the operation or age are incorporated immediately by the system's own experience in the calculation of OFVL.

Thus, the capacity of current systems for collecting, storing and processing data allows the extraction of characteristic parameters of our system and dynamic references that are compared to the static data that has worked until today.

The benefit of dynamic application of these references is a reduction of false alarms and therefore unnecessary interventions undertaken as a result, to enhance overall equipment effectiveness.

\section{REFERENCES}

[1] Galar, D., Berges , L. and Royo, J. (2009). “Overall Factory Vibration Level: The need for global indicators in CBM”. In Proceedings of COMADEM 2009.

[2] Girdhar P.2004. Practical Machinery Vibration Analysis and Predictive Maintenance. Oxford: Elsevier

[3] ISO 10816-1, Mechanical vibration. Evaluation of machine vibration by measurements on non-rotating parts .Parts 1-6

[4] Kim, S.-M., Joo, Y.-J., (2005), “Implementation of On-line Performance Monitoring System at Seoincheon and Sinicheon Combined Cycle Power Plant”, Energy, 30, pp. 2383-2401.

[5] Kumaraswamy. S. \& Rakesh. J. (2002). "Standardization of Absolute Vibration Level and Damage Factors for Machinery Health Monitoring”. In Proceedings of VETOMAC 2002.

[6] Parida, A., Phanse, K. and Kumar, U. (2004) “An Integrated Approach to Design and Development of e-Maintenance System”. ”. In Proceedings of ACSIM 2004 and VETOMAC 3 ,pp 1141-1147.

[7] Peters R. W. (2002). Maximizing Maintenance Operations for Profit Optimization: The Journey to Maintenance Excellence. The Maintenance Excellence Institute. Raleigh, North Carolina

[8] Reeves C. W. (1998). The Vibration Monitoring Handbook. Coxmoor Publishing Co. USA

[9] W. de Silva C. (1999). Vibration : fundamentals and practice. CRC Press LLC. USA

[10] Wyatt, C., (2004), “Monitoring Pumps”, World Pumps, December, pp. 17-21. 